\title{
Structural Analysis of the Interaction of Financial Managers' Competency Model
}

Submitted 05/05/21, 1st revision 15/06/21, 2nd revision 18/07/21, accepted 10/08/21

\author{
Seyyed Mohammad Hassan Mohammadi ${ }^{1}$, Akram Taftiyan $^{2 *}$, \\ Forough Heirani ${ }^{3}$, Saeed Eslami ${ }^{4}$
}

\section{Abstract:}

Purpose: Competent financial managers are a tool to develop and increase the organization's productivity as much as possible in changing economic conditions. Selecting the appropriate managers will improve the organization's decisions in all matters. Therefore, the present study aimed to investigate the structural analysis of the interaction of the categories of competency model of financial managers.

Design/Methodology/Approach: The research method was applied to purpose and descriptive correlation in terms of a data collection method in a cross-sectional period. In a quantitative method, research hypotheses were formulated and tested using a questionnaire. Then, 368 people were selected from professors and senior managers active in the capital market and financial managers by simple random sampling method. Hypotheses were tested by the structural equation method using PLS software. Confirmatory factor analysis using the leastsquares method was used to validate the 18 main variables and competency items of financial managers.

Findings: The structural analysis results indicate that causal, contextual, and intervening conditions have a significant effect on the central category phenomenon. The main category has a significant effect on strategies. In addition, strategies have a significant mediating effect on the relationships between the main categories on the consequences.

Practical Implications: The competency model of financial managers has a high ability to be implemented and can be used as an effective tool to select competent financial managers.

Originality/Value: To develop the issue of competence and efficiency of financial managers, the knowledge enhancement of this study leads to improving the foresight and decisions made by fate and highlights the importance of the dimensions of model categories for organizations.

Keywords: Competency, financial managers, structural equations.

JEL Classification: C58, G32.

Research type: Research paper.

\footnotetext{
${ }^{\text {I} P h . D ., ~ S t u d e n t, ~ D e p a r t m e n t ~ o f ~ A c c o u n t i n g, ~ Y a z d ~ B r a n c h, ~ I s l a m i c ~ A z a d ~ U n i v e r s i t y, ~ Y a z d, ~}$ Iran, Hassanmohammadi60@gmail.com;

${ }^{2}$ Corresponding Author, Assistant Professor, Department of Accounting, Yazd Branch, Islamic Azad University, Yazd, Iran, Taftiyan@iauyaz.d.ac.ir;

${ }^{3}$ Assistant Professor, Department of Accounting, Yazd Branch, Islamic Azad University, Yazd,Iran, Heyrani@iauyazd.ac.ir;

${ }^{4}$ Assistant Professor, Department of Accounting, Yazd Branch, Islamic Azad University, Yazd,Iran, Saeed.eslami@iauyazd.ac.ir;
} 


\section{Introduction}

Financial performance is facing a day that is probably the most significant period of change in its history. Process automation, the corporate digitalization agenda, and the ongoing need to protect assets and manage costs are putting significant pressure on and threatening financial professionals. It is time for CFOs and financial leaders worldwide to think about how to plan for future financial performance. Business expectations are rising. In addition to achieving operational, financial goals and maintaining the company's core line, financial managers are under constant pressure to provide strategic direction to the business to help make better decisions (Robert Half, 2020).

Selecting and recruiting skilled and professional managers is always one of the requirements of excellence in any organization (Anderson et al., 2014). The financial system is a set of integrated components that determine the financial functions of the market. The elements of this system interact with each other that the necessary knowledge of financial institutions and instruments and their role in economic growth and development can be obtained by recognizing these elements and understanding the relationships between them (Rahnama Roodi et al., 2013). Financial managers are involved in three fundamental decisions (Nikomram et al., 2009): 1) Investment decisions, 2) Financing decisions 3) Decisions related to profit sharing policies. Financial performance should become like a strategic, analytical, data-driven powerhouse that welcomes digitalization and drives performance, thereby increasing the value of the business. To successfully adapt to future financial performance, financial managers should have an efficient financial model, technologies, and, most importantly, highly skilled people (Robert Half, 2020).

The theories discussed are resource theory, including human resources, organizational resources, financial resources, and agency theory. The broader concept of financial manager ability for financial management includes planning-related competencies such as strategic financial competence and financial control competence. For a company to operate, it should provide resources to use these resources effectively and efficiently. The resource-based theory distinguishes between human, organizational, and financial resources (Barney, 1991).

Financial resources act as a catalyst in the resource acquisition process because they can be used to obtain resources (Alses et al., 2006). Previous research has shown that a company's resources, such as human capital and social capital, are significant for its development (Chandler, 1998; Davidson and Honig, 2003). While companies may lack substantial human resources from the start, a supporting parent company or social capital for easy access to resources under favorable conditions, qualifications, and CFOs in financial management can help to connect with resources. Competence of the financial manager in strategic financial management and the new company's growth following the competency-based approach facilitates strategic financial management (Gruber, 2007). As top management focuses on finance, goals are set, and financial 
plans are formulated, company resources are used more efficiently and effectively. As a result of better use of resources, the company's growth increases. Therefore, following the competency-based literature, the competence of strategic financial management increases the financial quality and the performance planning of the company.

This article aimed to broaden our understanding of the financial manager's responsibilities and competencies in new activities. These are 1- Competence of strategic financial planning 2-Competence of external financing 3-Competence of financing through operations 4- Competence of financial control. And then, it can take a step towards the development of financial managers and also be effective in senior managers' decisions by selecting suitable financial managers for the company's future by providing a practical model to the data processing method of the foundation and its structural analysis and turning it into a practical model.

The present study's findings can be used to operate and select the right financial managers and solve the financial challenges facing companies in the changing economic conditions related to the future. First, the theoretical foundations and research literature are inferred, and then the research background will be presented. Then, the research method is presented, including the method of implementing the research plan. According to the research methodology, validation of the research model and finally conclusions are presented and attempts to provide suggestions based on research findings as well as suggestions for future research, which is expected to address the challenges facing this area and make a small contribution to improving and enhancing the financial condition of companies.

\section{Literature Review}

\subsection{Competence of Financial Managers}

The issue of competence of managers, especially financial managers, is one of the most critical issues in the success of an organization. The competence of all managers in an organization is essential for the growth and excellence, and foresight of the organization. With the advancement of information technology, financial managers need to think more about their position than before because they need to maintain their position and interact with information technology. Previous research using a competency-based approach shows that solid experience and background can help overcome financial and capital constraints (Chandler, 1998). One group of researchers emphasizes the importance of strategic planning by financial managers for the success of new investment (Delmer and Sheen, 2003), while another group challenges this view (Bid, 2000). Strategic planning in finance is a vital part of new planning (Delmer and Sheen 2003). Strategic financial planning in new investments involves giving importance to the financial sphere, setting financial goals, and preparing a financial plan to achieve financial goals (McMahon, 2001; McMahon and Davis, 1994). 
Competence is a combination of skills, knowledge, and attitudes required to perform a role effectively (Huang and Ko, 2018). Abbasi Mosloo, Hosseini, and Zare (2015) found that the decision-making role of financial managers has the most significant impact on the growth and development of manufacturing enterprises. Asgari and Golehrudi (2014) concluded that in Iran, economic growth and development and the degree of openness of the economy have led to the expansion of financial development and the competence of financial managers has many benefits for organizations and managers at different levels. Likama (2015) states that the competencies of financial managers can affect the development of the organization and change management and implement the planned changes effectively. Rantz (2017) found that attention to the indicators such as freshness and extroversion, humility, patience, challenge, age, resistance to pressure, and patience play an essential role in the selection process. Aslan and Pamoko (2017) investigated the competence of managers and its impact on management levels, finding that the competence of managers affects the performance and development of people and the organization's performance.

Additionally, Mohebbi and Mohammadian (2017) concluded that managers' competence has four dimensions of interpersonal, individual, technical, or specialized and organizational competencies and the organizational competency subcomponent has the lowest average and the technical or specialized subcomponent has the highest average. Asheghi, Ghahremani, and Ghorchian (1996) reported that the competence of managers has five dimensions. These dimensions include intellectual-value, communication, technical-specialized, managerial, and ability dimensions. They stated that to develop the competencies of managers in the monetary and banking field, a model consisting of a central core should be included, such as the elements of managerial competencies and the community supporting the developmen of managers, which is the second layer influencing managers' development plans.

Abbaspour, Rahimian, Delavar, Ghiasi Nodooshan, and Hashemian (2017) concluded that appropriate training programs should be planned to improve managers' competencies to increase their skills and competencies competitive advantage by using the desired model of managers' competence. Furthermore, Safari, Jafarnejad, Yazdanpanah, and Bayati (2016) reported that having competent managers can improve the performance of the projects in which these managers work, and the most crucial competence field project management is risk management competence, which has been wholly neglected in projects. In a study, Wilgs (2014) examined the factors affecting the empowerment of managers and the effectiveness of financial management. The results of this study are the basis for the proposed empowerment and financial sustainability development plan. Rahimnia and Hoshyar (1991) reported a three-level model while researching the dimensions and components of the competency model of managers. The first level consists of four general areas of technical, environmental, managerial, and individual, the second level includes eight competency dimensions, including general knowledge, specialized knowledge, marketing, environmental awareness, subdivision management, human resource management, interpersonal communication, and interpersonal communication and the 
third level consists of forty-two specialized and operational components of competency. Aslan (2017) researched the competencies required to have an effective manager and described the impact of those competencies at different levels of management. The competency model can provide a clear picture of knowledge, skills, experience and personal characteristics required by employees and managers as critical decision-makers in the face of disrupted internal and external organizational issues have an effective and decisive role in the success and failure of the organization (Kermani, Darvish, Sarlak, and Kolivand, 2017).

Adorned, Hoseinpour, Izdivo Bostani Amlishi (2018), in a study, found that seven competencies, including personality traits, skills, abilities, public reputation, attitude and insight, knowledge, professional reputation, are the most critical factors of managers' competence. Motlagh and Alvani (2015), in a study examined the relationship between spirituality in the workplace and human resources and organizational performance. They show that trust, caring for employees' human values, flourishing human resource creativity, a sense of purposefulness, and increasing organizational productivity has the most significant impact on each model variable. Based on what was mentioned above, the issue of competency of financial managers in the developing country of Iran is still at the beginning of the road. It needs more extensive research to provide and evaluate the competency model of financial managers that leads to the growth and development of the organization and achieve future goals.

\subsection{Competency Model of Financial Managers}

The competence of financial managers and their influential role in the current and future decisions of the organization is an undeniable role. Especially in the developing country of Iran, which has an increasing need to employ competent managers in all sectors, especially the financial sector. Therefore, providing an efficient and fruitful competency model can help organizations achieve the above goal as much as possible in a situation where science is constantly advancing. One of the branches of science that have high progress in all fields is the growth of information technology.

Financial systems that are becoming more complete and comprehensive every day than the previous day are prominent examples of this growth. If the organization does not have competent financial managers, it can never go on the path of progress and development, and financial managers are content only with the reports of financial systems. Competent and insightful financial managers constantly adapt to the systems and try to show more of their role in achieving its goals. These roles include participation in critical decisions of the organization for the current situation and the future. Another vital role is to give strategic insight to the organization, which is one of the most critical roles of financial managers in the current economic situation. According to this model and its strategies and methods, paying attention to them can help the organization choose and select the right financial managers. 
Therefore, after studying the theoretical foundations and analyzing the interviews, the main and sub-categories of the competency model of financial managers were developed after review, open, central, and selective coding, which was then presented in a graph. According to Strauss and Corbin (2008), a foundation data theory can be presented diagrammatically and implicitly. According to the factors presented in the competency model of financial managers in Figure (1), the present study will be examined to construct and validate the factor structure of the data model of the competency foundation of financial managers. The hypotheses of the present study are as follows:

1- Causal, contextual, and intervening conditions have a significant effect on the central category phenomenon. 2- The main category has a significant effect on strategies. 3- Strategies have a significant mediating effect on the relationships between the main categories on the consequences.

Figure 1. Paradigm model of managers' competency model (Mohammadi et al., 2020).

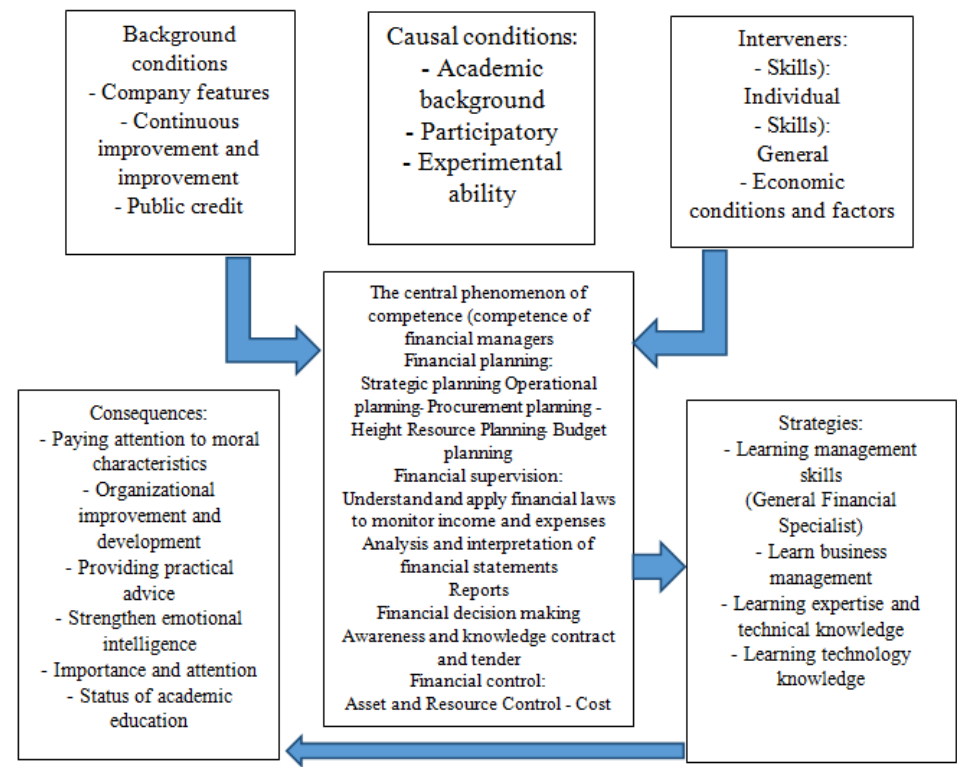

Source: Own creation.

\section{Research Methodology}

This research seeks to test the competency model of financial managers to prepare and present it to improve the decision and its analysis by users. The model constructed in this research is investigated by a quantitative method in a correlational survey. The data used in this study are small. Because the primary purpose of this research is to add to the existing literature and does not seek to review previous research, it is classified in the category of original research. In this research, we will also seek to 
explain the existing conditions to be in descriptive research. According to the whole approach, except for this research, which will test theories using data, it is inductive deductive research in terms of the type of argument. Since the data required for the research to write the theoretical foundations and research background section will be obtained from archival information, it is considered library research, and there is a questionnaire in the template test section. In this study, using a simple random sampling method, the statistical population was selected from among university professors working in accounting and management, senior managers and financial managers active in the capital market and companies and institutions, and 368 people participated.

The data collection method in this stage is the use of a researcher-made questionnaire whose hypotheses are extracted based on the dimensions and components of the proposed competency model of financial managers (Mohammadi et al., 2020) and distributed among the statistical sample. A 56-item tool with the main dimensions of "economic factors, giving importance to moral characteristics - strengthening emotional intelligence - income and resources - providing practical advice - the importance and consideration of the status of academic education - learning management skills (general - financial) - learning knowledge- learning technology Business management - Learning expertise and technical knowledge - Public reputation - Company characteristics - Continuous improvement - Personal skills General skills (competencies) - Individual skills (competencies) - Academic background - Experimental ability - and participatory was questioned. To evaluate the answers given, the items in this questionnaire were adjusted based on a 5-point Likert scale from very high (5) to very low (1).

It should be noted that all categories of the data theory paradigm model of the foundation with an alpha above 0.7 have a reasonable degree of reliability. Five experts also confirmed the validity of the content of the questionnaire. The data analysis method is based on structural equation modeling in terms of the least partial squares approach with Smart PLS 3 software. The measurement model included the reliability of indices (hybrid and alpha), convergent and divergent validity, and the structural model included path coefficient, significance, and coefficient of determination, which were used to test the hypotheses. Using PLS in this research is evaluating hierarchical models and the lack of need for presuppositions of normal data distribution and the solution of the problem of similarity of the measurement model, no missing data, remote data, and nonlinearity of data. Also, this method is predictive and can be used to build a theory.

\section{Results}

Considering that the measurement model is of a reflective type, first, reliability and validity have been studied, and then, factor structures between structures have been studied. Therefore, to evaluate the fit of the research model, three criteria of reliability, convergent validity, and divergent validity have been used. In other words, the 
reliability of the present study has been investigated through three criterio, Cronbach's alpha coefficient, combined reliability (one of the most critical tests of research reliability), and factor loading coefficients. Also, the test used for convergent validity, mean derivation average of 10 (AVE), and divergent validity, two methods of crossfactor loading, and Fornell and Larker 11 methods were used. Finally, in the last part of the tests of the present study, the path coefficients and significance, the coefficient of determination were evaluated.

\subsection{Measurement Model}

The research model was used in two implementations of standard coefficients and significant coefficients in the following figures. After this stage, all tests were performed based on the research model.

Figure 2. External pattern in the case of estimating standard coefficients

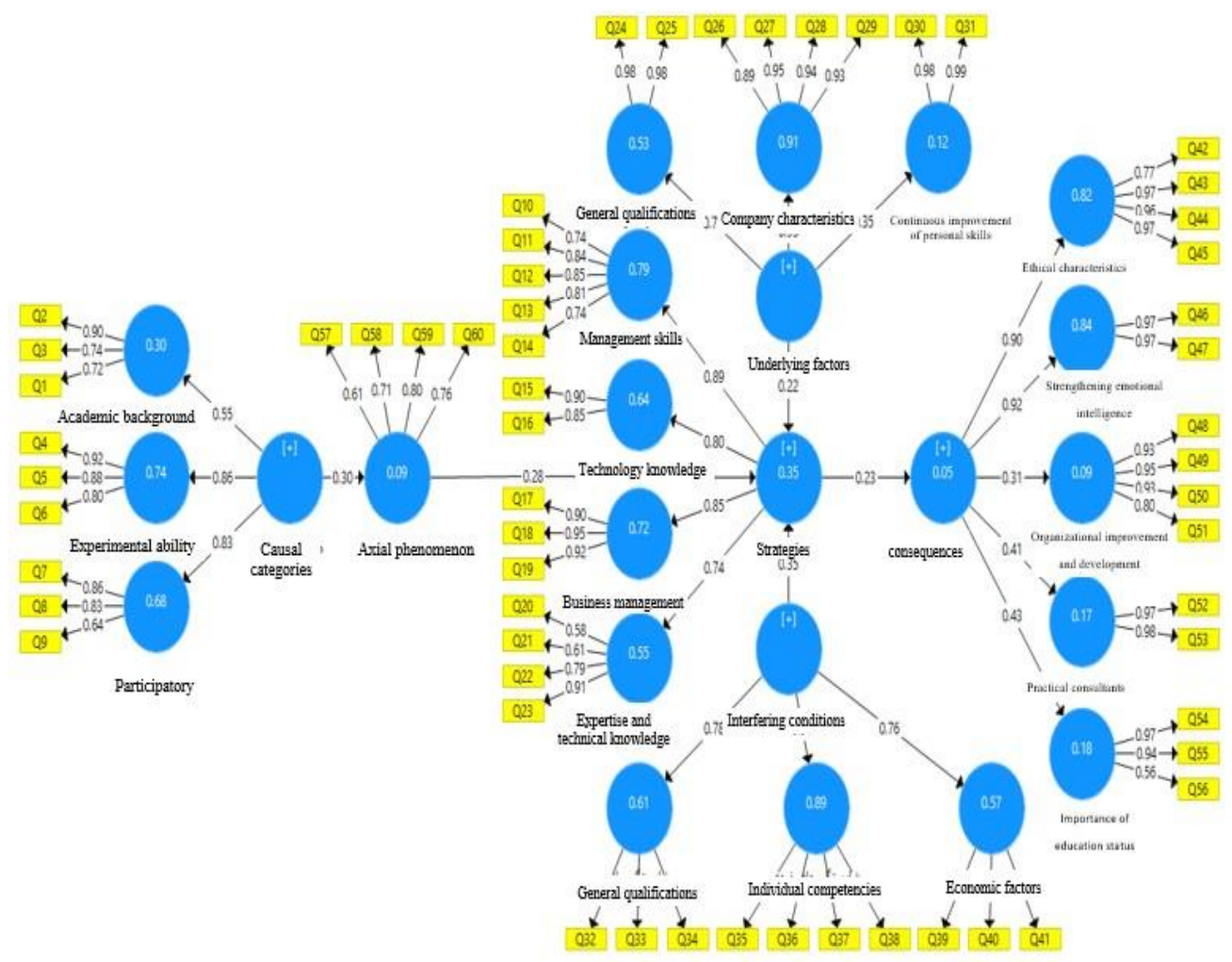

Source: Own creation.

Figure (2) shows the coefficients of the effect of exogenous variables (independent) on endogenous variables (dependent) at three levels of categories, dimensions, and indicators. To examine the significance of these coefficients, the t-statistics showed in Figure (3) are used. In addition, the significance of these coefficients in the analysis 
of the path of the categories in Table (2) has been investigated using statistics. For example, based on the coefficients of Figure (1), the coefficient of causal categories on the axial phenomenon is shown to be equal to 0.30 .

Figure 3. External pattern in the significant state of coefficients

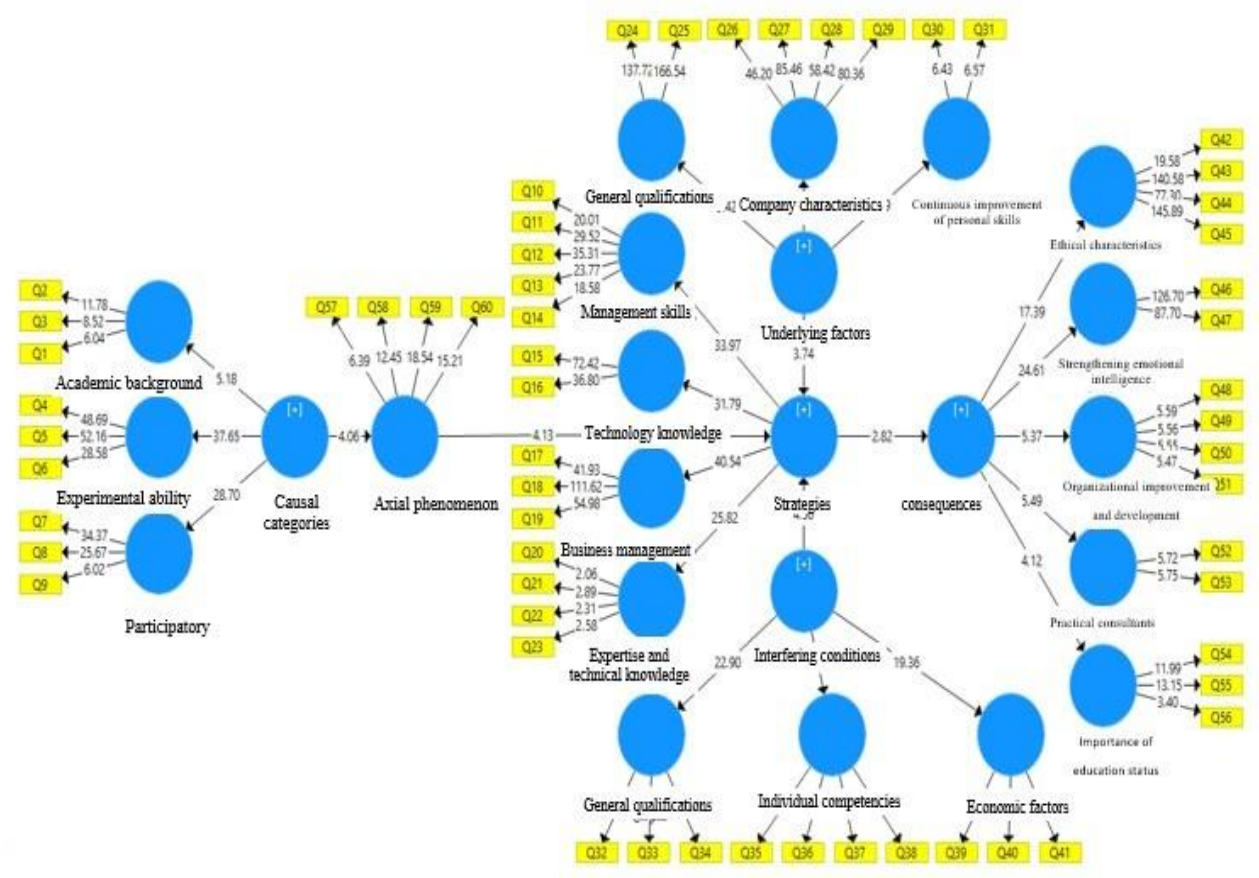

Source: Own creation.

Figure 2 shows the T-statistics for structural relationships at three relationships between categories, dimensions, and indicators. The statistics shown in the model paths are used to confirm the significant structural relationship between the model structures. If the T-statistics are more significant than 1.96, the relationships between the structures are confirmed at the $95 \%$ confidence level. For example, the value of the statistic of 4.06, which is shown in the relationship between the causal category on the axial phenomenon in Figure (2), confirms that there is a significant positive relationship between these two structures (categories) at the level (0.05).

In the internal (structural) pattern tests section using path analysis and the statistics shown in the path between the pattern categories in Figure (2), the significance of the relationship coefficients between the pattern categories for each path from the exogenous variable to the endogenous variable pattern is examined in the form of a structural relationship. 


\subsection{External Pattern Tests (Measurement)}

Four tests were performed to confirm the reliability of the model. The results of all four tests are shown in Table (1). The Cronbach's alpha value for each variable should be above 0.7. The results of Cronbach's alpha test of the research model in Table (1) show that all Cronbach's alpha coefficients are above 0.7. Structures with few boundary points are an acceptable coefficient of 0.6. Therefore, the reliability is confirmed based on this test.

Table 1. Cronbach's alpha coefficients, combined reliability (CR); Spearman correlation reliability and shared reliability

\begin{tabular}{|c|c|c|c|c|c|}
\hline $\begin{array}{c}\text { Mean } \\
\text { variance } \\
\text { extracted } \\
\text { (AVE) }\end{array}$ & $\begin{array}{c}\text { Spearman } \\
\text { correlation } \\
\text { reliability }\end{array}$ & $\begin{array}{l}\text { Composite } \\
\text { reliability }\end{array}$ & $\begin{array}{l}\text { Cronbach's } \\
\text { alpha } \\
\text { reliability }\end{array}$ & Subcategories (dimensions) & $\begin{array}{c}\text { Main } \\
\text { catego } \\
\text { ries }\end{array}$ \\
\hline 0.63 & 0.77 & 0.83 & 0.71 & Academic background & \multirow{4}{*}{$\begin{array}{c}\text { Causal } \\
\text { catego } \\
\text { ries }\end{array}$} \\
\hline 0.76 & 0.84 & 0.90 & 0.84 & Experimental ability & \\
\hline 0.61 & 0.76 & 0.82 & 0.70 & Participatory & \\
\hline 0.38 & 0.82 & 0.84 & 0.78 & Total & \\
\hline 0.67 & 0.86 & 0.90 & 0.86 & Management skills & \multirow{5}{*}{$\begin{array}{l}\text { Strateg } \\
\text { ies }\end{array}$} \\
\hline 0.76 & 0.70 & 0.86 & 0.69 & Technology knowledge & \\
\hline 0.86 & 0.92 & 0.95 & 0.92 & Business management & \\
\hline 0.54 & 0.41 & 0.82 & 0.80 & Expertise and technical knowledge & \\
\hline 0.38 & 0.90 & 0.86 & 0.84 & Total & \\
\hline 0.95 & 0.95 & 0.98 & 0.95 & Public credit & \multirow{4}{*}{$\begin{array}{l}\text { Backg } \\
\text { round } \\
\text { factors }\end{array}$} \\
\hline 0.86 & 0.95 & 0.96 & 0.95 & Company characteristics & \\
\hline 0.97 & 0.97 & 0.99 & 0.97 & $\begin{array}{c}\text { Continuous improvement of } \\
\text { personal skills }\end{array}$ & \\
\hline 0.55 & 0.91 & 0.90 & 0.87 & Total & \\
\hline 0.76 & 0.88 & 0.90 & 0.85 & General qualifications & \multirow{4}{*}{$\begin{array}{l}\text { Interve } \\
\text { ntion } \\
\text { conditi } \\
\text { ons }\end{array}$} \\
\hline 0.74 & 0.88 & 0.92 & 0.88 & Individual competencies & \\
\hline 0.87 & 0.93 & 0.95 & 0.93 & Economic factors & \\
\hline 0.55 & 0.91 & 0.92 & 0.91 & Total & \\
\hline 0.85 & 0.96 & 0.96 & 0.94 & Ethical characteristics & \multirow{6}{*}{$\begin{array}{c}\text { Outco } \\
\text { mes }\end{array}$} \\
\hline 0.94 & 0.94 & 0.97 & 0.93 & $\begin{array}{l}\text { Strengthening emotional } \\
\text { intelligence }\end{array}$ & \\
\hline 0.82 & 0.97 & 0.95 & 0.93 & $\begin{array}{c}\text { Organizational improvement and } \\
\text { development }\end{array}$ & \\
\hline 0.95 & 0.97 & 0.97 & 0.95 & Practical consultants & \\
\hline 0.71 & 0.94 & 0.88 & 0.79 & Importance of education status & \\
\hline 0.33 & 0.92 & 0.83 & 0.82 & Total & \\
\hline 0.53 & 0.72 & 0.81 & 0.70 & Axial phenomenon & \\
\hline
\end{tabular}

Source: Own creation.

The internal correlation of the questions of one variable (within the model) is called combined reliability (CR). Within the model, factor load coefficients, errors, path 
coefficients, and other parameters affect the correlation of the questions. Therefore, the most critical reliability test is the combined reliability test because the relationship between the questions is examined based on the model's components. In the newly discovered model (like the model of the present study), CR $<0.6$ is sufficient, and if the model is in the maturation stage (a pattern that has been studied many times), i.e., it is CR> 0.95, it is good (Yarbiki Langroudi, Kurdistani, Rezaei, 2020). The results of the combined reliability test in Table (2) show that all the coefficients of the combined reliability are above 0.7 ; the reliability based on this test is also confirmed. Spearman correlation coefficient for each structure should be greater than 0.7 (rho_A> 0.7 ).

The Spearman correlation reliability test results in Table (1) shows that all Spearman correlation reliability coefficients are above 0.7 . Therefore, the reliability of the model based on this criterion is also confirmed. The Common Reliability Test examines the power of generalizability and reproducibility of results in other studies each year alone, apart from other questions. The value of the shared reliability coefficient should be greater than (Communality <0.5).

The results of the standard reliability test of structures are also shown in Table (1). All coefficients of shared reliability of structures are above 0.5 , so the shared reliability of the questions is also confirmed. Based on the four reliability tests performed, it can be concluded that the research model is reliable. The measuring characteristics of each structure should converge with each other. Convergent validity tests include two tests. The first test of convergent validity using the extracted mean-variance (AVE) criterion, and the second test using the values of the extracted mean-variance (AVE) with the combined reliability coefficients (CR), both of which are shown in Table (2).

The results of the first and second convergent validity tests can be extracted from Table (1). According to Hensler et al. (2009), the mean values of extractive variance (AVE) for each variable should be above 0.5 . According to the information shown in Table (1), all values of the mean extracted variance of the structures are higher than 0.5 , and the validity of the model is confirmed. In the second convergent validity test, the values of the combined reliability coefficients should be higher than the mean (CR> AVE). As the results in Table (1) show, the second condition of convergent validity (CR> AVE) is met in all cases. Therefore, the convergence validity of the model is confirmed.

In divergent validity tests, it is found that one structure measures its structure and deviates from the questions of other structures. Divergent validity tests are examined in which the researcher cannot omit a year or a variable to modify the pattern. Divergent validity can be calculated in two ways: a) comparing the correlation of the characteristics of a structure with that structure versus the correlation of those characteristics with other structures (divergent validity by the method of reciprocal factor loads) b) comparing the degree of correlation of a structure with its characteristics against the correlation of that structure with other structures (divergent 
validity by Fornel and Larker method). Due to the compactness of the article, only divergent validity has been reported by the Fornell Larker method.

Table 2. Divergent validity by Fornell and Larker method

\begin{tabular}{|c|c|c|c|c|c|c|c|c|c|c|c|c|c|c|c|c|c|c|c|c|}
\hline & & 1 & 2 & 3 & 4 & 5 & 6 & 7 & 8 & 9 & 10 & 11 & 12 & 13 & 14 & 15 & 16 & 17 & 18 & 19 \\
\hline & 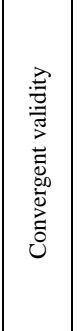 & 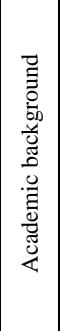 & 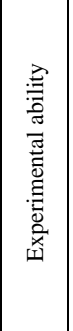 & 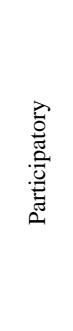 & 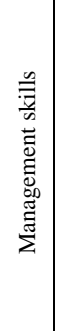 & 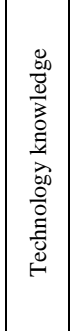 & 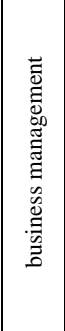 & 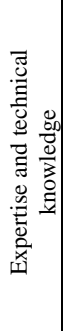 & 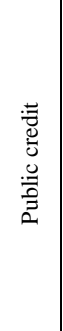 & 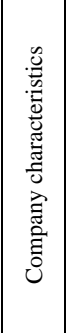 & 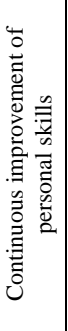 & 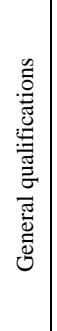 & 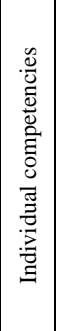 & 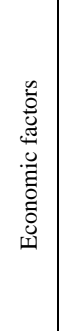 & 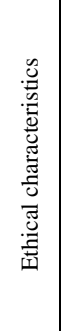 & 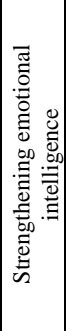 & 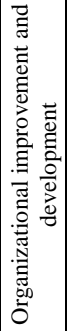 & 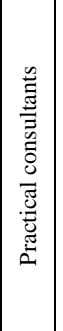 & 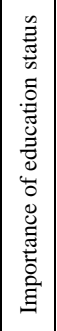 & 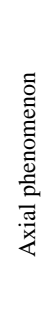 \\
\hline 1 & 0.629 & 0.79 & & & & & & & & & & & & & & & & & & \\
\hline 2 & 0.756 & 0.22 & 0.87 & & & & & & & & & & & & & & & & & \\
\hline 3 & 0.613 & 0.27 & 0.56 & 0.78 & & & & & & & & & & & & & & & & \\
\hline 4 & 0.635 & 0.12 & 0.31 & 0.53 & 0.8 & & & & & & & & & & & & & & & \\
\hline 5 & 0.759 & 0.05 & 0.3 & $0.35 \cdot /$ & 0.58 & 0.87 & & & & & & & & & & & & & & \\
\hline 6 & 0.856 & 0.15 & 0.18 & 0.25 & 0.56 & 0.63 & 0.93 & & & & & & & & & & & & & \\
\hline 7 & 0.541 & 0.39 & 0.29 & 0.15 & 0.16 & 0.05 & 0.03 & 0.73 & & & & & & & & & & & & \\
\hline 8 & 0.954 & 0.03 & 0.07 & 0.23 & 0.38 & 0.18 & 0.25 & -0.03 & 0.98 & & & & & & & & & & & \\
\hline 9 & 0.86 & 0.11 & 0.23 & 0.24 & 0.38 & 0.28 & 0.26 & 0.15 & 0.53 & 0.93 & & & & & & & & & & \\
\hline 10 & 0.971 & 0.2 & 0.34 & 0.05 & 0.01 & 0.03 & -0.04 & 0.2 & -0.02 & 0.27 & 0.99 & & & & & & & & & \\
\hline 11 & 0.758 & 0.13 & 0.03 & 0.14 & 0.17 & 0.15 & 0.38 & -0.18 & 0.26 & 0.23 & -0.04 & 0.87 & & & & & & & & \\
\hline 12 & 0.741 & 0.33 & 0.11 & 0.26 & 0.4 & 0.19 & 0.44 & -0.17 & 0.36 & 0.22 & -0.07 & 0.71 & 0.86 & & & & & & & \\
\hline 13 & 0.871 & 0.12 & 0.16 & 0.2 & 0.38 & 0.29 & 0.42 & -0.21 & 0.35 & 0.24 & 0.03 & 0.3 & 0.59 & 0.93 & & & & & & \\
\hline 14 & 0.849 & $\begin{array}{c}- \\
0.18\end{array}$ & $\mid-0.13$ & -0.08 & 0.02 & 0.18 & 0.06 & -0.24 & 0.01 & -0.07 & -0.13 & $\begin{array}{c}- \\
0.08\end{array}$ & $\mid \begin{array}{c}- \\
0.12\end{array}$ & 0.03 & 0.92 & & & & & \\
\hline 15 & 0.936 & -0.2 & -0.04 & 0.08 & 0.17 & 0.26 & 0.1 & -0.21 & -0.01 & -0.01 & -0.08 & 0.01 & $\begin{array}{c}- \\
0.05\end{array}$ & 0.1 & 0.85 & 0.97 & & & & \\
\hline 16 & 0.821 & 0.07 & 0.11 & 0.25 & 0.44 & 0.25 & 0.22 & 0.18 & 0.31 & 0.37 & 0.11 & 0.01 & 0.22 & 0.32 & 0.03 & 0.14 & 0.91 & & & \\
\hline 17 & 0.95 & 0.39 & 0.27 & 0.09 & 0.02 & -0.04 & 0.07 & 0.41 & 0.09 & 0.33 & 0.38 & 0.01 & 0.1 & 0.17 & -0.06 & -0.04 & 0.4 & 0.97 & & \\
\hline 18 & 0.714 & 0.29 & 0.015 & 0.12 & 0.13 & 0.22 & 0.13 & 0.11 & 0.27 & 0.27 & 0.01 & 0.19 & 0.16 & 0.18 & 0.2 & 0.25 & 0.02 & 0.24 & 0.85 & \\
\hline 19 & 0.53 & 0.22 & 0.24 & 0.24 & 0.39 & 0.25 & 0.27 & 0.27 & 0.13 & 0.22 & 0.05 & 0.07 & 0.19 & 0.07 & -6.06 & 0.01 & 0.15 & 0.19 & 0.15 & 0.72 \\
\hline
\end{tabular}

\section{Source: Own creation.}

According to the contents of Tables (2), according to Fornell and Larker (1981), in order to examine divergent validity, it is done by the matrix that one component should have more distinction and distinction among its observables (questions) than other components to say that the component in question has high divergent validity. In divergent validity, we seek to answer the question to what extent can a factor in competition with external, unrelated, and uncalculated factors explain the variance of 
the set of questions? If a factor estimates the most significant amount of variance within a set of questions and shows less correlation with unrelated factors, it has divergent validity. In other words, the root of the convergent validity of each component is greater than the maximum correlation of that component with other components (Fornell and Larker, 1981). The values show an excellent divergent validity in Fornell and Larker methods. It should be noted that in Fornell Larker divergent validity, the aim is to determine the divergence between each structure and other structures in the model, so since second-order structures consist of their firstorder structures, they should not diverge with their first-order structures (Davari, Rezazadeh, 2014). As a result, the second-order structure (causal categories, strategies, contextual factors, intervening conditions, consequences) was removed from the column and row of the Fornell-Larker matrix table.

\subsection{Internal Pattern Tests (Structural)}

Statistical test is used to examine and analyze the structural path of pattern categories. The value and symbol of the statistics coefficient are used to determine the significance of the coefficients and the direction of the path. The results of t-test, which is extracted from the modified external model in the significant state of coefficients (Figure 2), are shown in Table (3).

Table 3. Significance coefficients and statistics $t$

\begin{tabular}{|c|c|c|c|c|c|c|c|}
\hline Hypothesis & $\begin{array}{c}\text { Path } \\
\text { coeffici } \\
\text { ent }\end{array}$ & $\begin{array}{c}\text { Significa } \\
\text { nce } \\
\text { factor }\end{array}$ & $\begin{array}{c}\text { The } \\
\text { coefficient of } \\
\text { determination }\end{array}$ & $\begin{array}{c}\text { Effe } \\
\text { ct } \\
\text { size }\end{array}$ & \multicolumn{2}{|c|}{$\begin{array}{c}\text { Significan } \\
\text { ce level }\end{array}$} & \multicolumn{2}{|c|}{$\begin{array}{c}\text { Bootstrap security } \\
\text { intervals }\end{array}$} \\
\hline $\begin{array}{c}\text { Casual } \\
\text { categories- } \\
\text { axial } \\
\text { phenomenon }\end{array}$ & 0.3 & 4.06 & 0.09 & 0.1 & 0.000 & 0.16 & 0.47 \\
\hline $\begin{array}{c}\text { Axis } \\
\text { Phenomena } \leftarrow \\
\text { Strategies }\end{array}$ & 0.28 & 4.13 & & 0.12 & 0.000 & 0.14 & 0.42 \\
\hline $\begin{array}{c}\text { Background } \\
\text { Strategies- } \\
\text { strategies }\end{array}$ & 0.22 & 3.74 & 0.35 & 0.06 & 0.000 & 0.09 & 0.32 \\
\hline $\begin{array}{c}\text { Interventionist } \\
\text { Strategies- } \\
\text { Strategies }\end{array}$ & 0.35 & 4.5 & & 0.16 & 0.000 & 0.02 & 0.05 \\
\hline $\begin{array}{c}\text { Strategies } \leftarrow \\
\text { Consequences }\end{array}$ & 0.23 & 2.87 & 0.05 & 0.05 & 0.007 & -0.09 & 0.04 \\
\cline { 6 - 9 }
\end{tabular}

Source: Own creation.

The structural analysis of the indirect and mediating effects of strategies on the relationship between causal conditions, contextual factors, and intervening conditions with consequences was discussed. As shown in the table above, the pivotal phenomenon has a positive and significant effect on the relationship between causal "categories" and strategies $(\beta=0.087, \mathrm{t}=2.57, \mathrm{p}<0.01)$. The central phenomenon leads to an increase in the relationship between causal "categories" and strategies. In 
131

addition, strategies have a positive and significant effect on the relationship between the axial phenomenon and the consequences $(\beta=0.064, \mathrm{t}=2.62, \mathrm{p}<0.01)$, indicating that as strategies increase, the relationship between the axial phenomenon with consequences increases. Strategies have a positive and significant effect on the relationship between contextual factors and outcomes $(\beta=0.049, \mathrm{t}=2.58, \mathrm{p}<0.011)$, which means that the relationship between contextual factors and consequences increases with increasing strategies.

Strategies have a positive and significant effect on the intervening situation with consequences $(\beta=0.078, \mathrm{t}=2.72, \mathrm{p}<0.008)$, which means that by increasing the strategies, the relationship between the intervening situation and the consequences increases. Finally, there is a positive and significant effect on the axioms and strategies in the relationship between causal categories and consequences $(\beta=0.05, t=2.45, p$ $<0.014)$, indicating that increasing the central phenomenon and strategies, respectively, leads to an increase in the relationship between causal "categories" and consequences.

\subsection{General Pattern}

After performing the tests of the first and second stages, i.e. the tests of fitting the measurement and structural relations of the model, respectively, it is the turn of the third stage test, i.e. the general test of the model in terms of fitting the measurement and structural relations in general. To fit the general pattern, there is a criterion called GOF, which is the square root of the average common values of the variables in the mean values of $\mathrm{R}^{2}$, three values of $0.01,0.25,0.35$ are used as weak, medium and strong values for comparison. Equation (1):

$\sqrt{0.71 * 0.47}=-0.577=\sqrt{\text { onvergent validity } * \text { Good fit coefficient of determination }}$

\section{Discussion and Conclusion}

One of the most critical issues that make the need to address financial managers' competence even more critical is the increasing use of artificial intelligence and system learning, which requires financial managers to adapt and update themselves. Business partners, conscientious objectors, risk managers, storytellers! These different names call senior financial managers in companies. Drin Roman, Chief Financial Officer (CFO), says the role of Chief Financial Officer in overseeing the financial world has become a business partner.

Today, CFOs extend their support to CEOs in strategic decisions and partner with CEOs. This financial aspect is expected to become more critical in 2020. Second, the increasing use of technology is further changing the role of financial managers. The use of data analytics in finance is rapidly increasing, and its importance cannot be overemphasized. This is another trend that is likely to continue in 2020 with the formation of finance. The use of technology has dramatically affected financial 
performance. The biggest challenge for financial leaders is to stay on top of technology while they play a crucial role in business partners. Understanding the global business environment and mitigating geopolitical risks are essential tasks that financial managers must work on strategically. The use of data analysis and artificial intelligence is increasing and reducing dependence on human intervention.

Financial managers need to adapt to these rapid and highly skilled changes if necessary. It is important to note that the financial performance of the nervous system is essential to the company. In many countries, the ethics officer is the only financial controller capable of seeing the entire company review financial transactions. Accordingly, providing a practical competency model for selecting financial managers will satisfy stakeholders. Therefore, the business unit's selection of competent financial managers will have practical consequences such as reducing incidental costs such as agency costs and lack of adequate capital and investment.

In the present study, the structural equation modeling technique was used to validate and strengthen the generalizability of the future information disclosure pattern results. The research findings confirmed the factor structure of the data model of the financial managers' competency foundation. The results of statistical tests confirmed the convergent and divergent reliability and validity of the competency model of financial managers. In other words, the fit of the model and its predictive power were high and appropriate. In fitting the structural model, the hierarchical structure of financial managers' competency categories was examined. The relationships between the categories were causally confirmed. The standardized coefficient of factor loads was determined and used for the significance of t-path coefficients, which confirmed the accuracy of the relationship between the components at a confidence level of $95 \%$ and above.

These findings indicate the relationship between categories. To determine the intensity of the effect of the exogenous variable (causal, contextual, intervening, main category) on the endogenous variable (strategies and consequences), the criterion of coefficient of determination was used, and its results were reported in the findings section. The predictive power criterion of the model was that the sum of squares of predictive errors in the manifest variables was more than zero, indicating the high quality of the overall model of the measurement sections and with the structural sections.

In fitting the measurement model, the two conditions of instrument reliability and validity were examined and established, and comprehensive criteria and methods were used. Three reliability indicators, including internal homogeneity, item reliability, and composite reliability, were used. Cronbach's alpha coefficient was used for the reliability and validity of the structures, which determines the degree of internal consistency, and composite reliability, which is a measure of superiority over Cronbach's alpha coefficient. In the present study, two indicators of component validity, including convergent and divergent validity, were investigated. Convergent validity measures the mean-variance or correlation of one-component questions with 
each other, and divergent validity measures the differentiation and independence of factors that are even theoretically similar but independent, both of which were in good condition. One of the indicators in evaluating concepts and structures is their applicability. In this regard, it is necessary to pay attention to the applicability of measuring the competency model of financial managers and then the tool that can make it operational.

As the results showed, the theoretical foundations and elements of the competency model of financial managers were appropriate to the present study results. Then, the number of competency model categories of financial managers into six main categories (causal, contextual, intervening, pivotal, leadership, consequences) was determined by examining the researcher in the existing literature. CFOs were validated, and finally, the present model was fitted with structural equation modeling.

According to the findings of the first hypothesis and proving the direct relationship and significance of causal conditions on the competence of financial managers (main category) with the results of research by Aslan (2017), Kang et al. (2015), the findings of Arasteh, Hassanpour, Izdio Bostani Amlishi (2018) were consistent. Also, the second hypothesis that there is a direct relationship between the background conditions and the competence of financial managers has become significant. Then, the effect of intervening conditions on the competence of financial managers was tested, and the hypothesis was confirmed. Daneshfard and Safari (2015) stated that individual and general factors and competencies are significant for a financial manager. Also, Asgari and Golehroudi (2014) considered the role of managers in economic development important and considered economic factors to show a financial manager's competence effectively, and the result of this hypothesis was consistent with the above research. Finally, it can be stated that according to the results obtained from the competence of financial managers and its significance, in most studies (Gholamzadeh, Sehhat, and Sattari Laghab, 2013; Motlagh and Alwani, 2018; Wilgs, 2014; Hee, Chen, and Hu, 2019) also emphasize these consequences.

According to the integrated and comprehensive classifications of the central phenomenon studied under the title of competency of financial managers, the findings of this study show the influential factors to facilitate the movement towards it. Based on the research results, professional institutions such as IMA (Management Accounting Association) can develop the necessary conditions to improve the selection of qualified financial managers and develop and implement models related to the competence of financial managers. On the other hand, companies also benefit from developing standard templates and using them in selecting the right managers.

Attracting competent and forward-looking financial managers by companies and holding stakeholders accountable for their selection by companies is one of the knowledge enhancements of this research that will improve the company's quality and organization of crucial current and future decisions. Therefore, it is suggested that public and private organizations use codified and standardized models prepared by 
professionals in this field. Additionally, other researchers can conduct new research based on the findings of this study to design and develop other models. In addition, it is necessary to establish coordination and consistency between public and private organizations and companies to implement the appropriate central model of financial managers with a forward-looking approach. Otherwise, an appropriate level of effective decisions in the present and future conditions cannot be achieved.

As a result, by applying the above models, it was possible to compare the company's situation with the conditions before and after the implementation of these models and the role of financial managers in the company's development (Asgari and Golehrudi 2014; Abbasi Mosul, Hosseini, and Zare 2015). Accordingly, it can be concluded that this will lead to forming a suitable platform for the use of codified and standard templates in different companies. Therefore, the present study has examined and evaluated many features and factors affecting the level and quality of the effective model in identifying qualified financial managers.

Among the future proposals, the provision of forward-looking models should be considered in selecting suitable financial managers. It also seems that the rate of companies' use of these models varies according to the conditions of governance and representation, so it is recommended that researchers study and test this in their studies. Besides, other researchers can compare the results of their research with this research to expand literary studies in this field. Finally, it is suggested that in the coming years and after the development of prospective standard models in this field, the effectiveness of these models in companies active in the capital market should also be examined.

\section{References:}

Abbasi Mosul, K., Hosseini M.T., Zare, S.H. 2015. The Role of Financial Managers in the Development and Progress of Manufacturing Enterprises. International Conference on New Research in Management, Economics and Accounting, Istanbul, Ilia Capital Institute of Idea Managers.

Abbaspour, A., Rahimian, H., Delaware, A., Ghiasi Nodooshan, S., Hashemian, F. 2017. Development of managers of the National Iranian Gas Company based on competency model. Quarterly Journal of Educational Psychology, 43, 59-73.

Alsos, G.A., Isaksen, E.J., Ljunggren, E. 2006. New venture financing and subsequent business growth in men- and women-led businesses. Entrepreneurship Theory and Practice, 30(5), 667-686.

Andersson, H., Sundstrom, B.W., Nilsson, K., Ung, E.J. 2014. Competencies in Swedish emergency departments - The practitioners' and managers' perspective. International Emergency Nursing, 22(2), 81-87.

Arasteh, H., Hassanpour, A., Izadi, A., Bostani Amlishi, T. 2018. Designing a Competency Model for Public Relations Managers Case Study: National Iranian Gas Company and its Subsidiaries-Human Resources Training and Development, 50, 18-29.

Asgari, M.R., Ahmadian Gole Rudi, S. 2014. Financial Management and Its Role in Economic Development of Communities. The First National Conference on 
Management and Accounting in the New World of Business, Economics and Culture, Aliabad Katoul, Islamic Azad University, Aliabad Katoul Branch.

Asheghi, H., Ghahremani, M., Ghorchian, N.G. 2017. Identifying and explaining the dimensions, components and indicators of competency development of managers in the banking industry. Quarterly Journal of Human Resources Education and Development, 14, 57-76.

Aslan, M., Pamukcu, A. 2017. Managerial competencies and impact on management levels. International Journal of Advanced Research in Management and Social Sciences, 6(9), 1-15.

Barney, J. 1991. Firm resources and sustained competitive advantage. Journal of Management, 17(1), 99-120.

Belinda, V. 2014. Factors influencing administrators empowerment and financial management effectiveness. Procedia-social and Behavioral Sciences, 76, 466475.

Bhide, A. 2000. The origin and evolution of new businesses. New York: Oxford University Press.

Chandler, G.N. 1998. An examination of the substitutability of founder's human and financial capital in emerging business ventures. Journal of Business Venturing, 13(5), 353-369.

Chandler, G.N., Honig, B., Wiklund, J. 2005. Antecedents, moderators, and performance consequences of membership change in new venture teams. Journal of Business Venturing, 20(5), 705-725.

Davidsson, P., Honig, B. 2003. The role of social and human capital among nascent entrepreneurs. Journal of Business Venturing, 18(3), 301-331.

Delmar, F., Shane, S. 2003. Does business planning facilitate the development of new ventures? Strategic Management Journal, 24(12), 1165-1185.

Gruber, M. 2007. Uncovering the value of planning in new venture creation: A process and contingency perspective. Journal of Business Venturing, 22(6), 782-807.

Hwang, H., Kuo, T. 2018. Competency in delivering health education: A concept analysis. Journal of Interprofessional Education \& Practice, 11, 20-25.

Kermani, B., Darwish, H., Sarlak, M.A., Kolivand, P.H. 2017. Designing the competencies model of hospital managers. Journal of Health Promotion Management, 7(2), 5864.

Liikamaa, K. 2015. Developing a project manager's competencies: A collective view of the most important competencies. Procedia Manufacturing, 3, 681-687.

McMahon, R.G.P. 2001. Business growth and performance and the financial reporting practices of Australian manufacturing SMEs. Journal of Small Business Management, 39(2), 152-164.

McMahon, R.G.P., Davis, L.G. 1994. Financial reporting and analysis practices in small enterprises: Their association with growth rate and financial performance. Journal of Small Business Management, 32(1), 9-17.

Mohebbi, A., Mohammadian Shamim, M. 2017. Designing the competency model of managers and training experts of East Tehran Police Command. Quarterly Journal of Resource Management in Law Enforcement, 20, 146-164.

Nikomram, H., Rahnamaye R.F., Hibati, F. 2009. Fundamentals of Financial Management, Vol. 1 and 2, Termeh Publications, Fourth Edition.

Rahnamaye Roodpashti, F. 2013. Fundamentals of Financial Marketing: The Importance and Necessity of Recognizing It in Financial Management Based on Theoretical 
Approach. Investment Knowledge Quarterly (Iranian Financial Engineering Association), 2(6), 1-14.

Rahnamaye Roodpashti, F., Taghavi, M., Shahverdiani, S. 2011. Financial Deepening and Development of the Financial System. Control, 5(4), 15-28.

Rantz, A. 2016. Competencies: Report of the competencies workgroup, workforce and succession planning workgroup. New York State Governors Office of Employee Relations and the Department of Civil Service.

Robert Half. Finance. 2020. Closer than you think. https://www.roberthalf.com.au/researchinsights/finance2020.

Sabet Motlagh, M., Alwani, S.M. 2018. Designing a model of the relationship between spirituality in the workplace and human resource performance and organizational performance. Productivity Management, 12(46), 39-67.

Safari, H., Jafarnejad, A., Yazdanpanah, A.A., Bayati, A. 2016. The relationship between a competent project manager and project performance: Risk management competence, important but neglected. Quarterly Journal of Human Resource Management in the Oil Industry, 36, 23-41.

Strauss and Corbin. 2008. Principles of Qualitative Research Methodology: The Basic Theory of Procedures and Methods, Translated by Buick Mohammadi. Tehran: Institute of Humanities and Cultural Studies.

The Association of Chartered Certified Accountants (ACCA). 2016. Professional accountants - the future: Drivers of change and future skills. ACCA6. 